\title{
Cholinergic modulation of response gain in the rat primary visual cortex
}

SUBJECT AREAS:

NEUROSCIENCE

VISUAL SYSTEM

STRIATE CORTEX

NEUROPHYSIOLOGY

Received

24 September 2012

Accepted

27 December 2012

Published

31 January 2013

Correspondence and requests for materials should be addressed to S.S. (shimegi@vision. hss.osaka-u.ac.jp)

\author{
Shogo Soma', Satoshi Shimegi ${ }^{1,2}$, Naofumi Suematsu' \& Hiromichi Sato ${ }^{1,2}$
}

1Graduate School of Frontier Biosciences, Osaka University, 1-17 Machikaneyama, Toyonaka, Osaka, 560-0043, Japan,
${ }^{2}$ Graduate School of Medicine, Osaka University, 1-17 Machikaneyama, Toyonaka, Osaka, 560-0043, Japan.

Acetylcholine (ACh) is known to modulate neuronal activity in the rodent primary visual cortex (V1). Although cholinergic modulation has been extensively examined in vitro, far less is understood regarding how ACh modulates visual information processing in vivo. We therefore extracellularly recorded visual responses to drifting sinusoidal grating stimuli from V1 of anesthetized rats and tested the effects of ACh administered locally by microiontophoresis. ACh exerted response facilitation or suppression in individual neurons across all cortical layers without any laminar bias. We assessed ACh effects on the stimulus contrast-response function, finding that $\mathrm{ACh}$ increased or decreased the response to varying stimulus contrasts in proportion to the magnitude of the control response without changing the shape of the original contrast-response function, which describes response gain control but not contrast gain control. Our results indicate that $\mathrm{ACh}$ serves as a gain controller in the visual cortex of rodents.

holinergic neurons in the basal forebrain widely project throughout the cerebral cortex ${ }^{1-3}$, modulating various brain functions including sensation ${ }^{4,5}$, attention ${ }^{6-8}$, learning and memory ${ }^{9}$, and cognitive reinforcement ${ }^{10}$ via acetylcholine $(\mathrm{ACh})$ released from their axon terminals. In vision, $\mathrm{ACh}$ modulates information processing in the primary visual cortex $(\mathrm{V} 1)$ of various species including primate ${ }^{11-16}$, tree shrew $^{17}$, and cat $^{18-22}$. Those studies demonstrated that ACh modulates not only the magnitude of the visual response $e^{11,12,15,20}$, but also the selectivity to stimulus-features such as orientation, direction, and size ${ }^{14,16-19,21,22}$. Moreover, some studies have found that ACh is involved in the gain control of the visual response ${ }^{11,12,15,17,20}$. For example, lesioning the cat basal forebrain remarkably reduces the magnitude of the visual response of V1 neurons, while the microiontophoretic administration of $\mathrm{ACh}$ restores the response ${ }^{20}$. Recent studies using primates have reported that the microiontophoretic administration of $\mathrm{ACh}$ receptor $(\mathrm{AChR})$ agonists predominantly facilitates the visual response by increasing the response gain of the contrast-response function in V1 neurons ${ }^{11,15}$. These findings raise an important question about the functional role of ACh; that is, does ACh ubiquitously act as a gain controller in the visual cortex of many mammalian species including rodent? The rodent is of special interest because it is a common animal model for the study of cortical circuits by far-ranging methods including genetic, anatomic, physiological, and behavioral techniques ${ }^{6-10,23,24}$, and therefore is expected to enhance our understanding of cholinergic modulation in visual information processing.

Although there are a number of studies on cholinergic modulation in rodent visual cortex, most come from brain slices ${ }^{25-31}$. In contrast, there are comparatively far fewer in vivo studies on this topic, especially on the stimulus-response relationship ${ }^{24}$. Therefore, we investigated the effects of ACh on stimulus contrast-response tuning using microiontophoretic $\mathrm{ACh}$ administration. We found that $\mathrm{ACh}$ facilitated or suppressed the visual responses of individual cells and modulated the gain of the contrast-response function. Thus, $\mathrm{ACh}$ act as a gain controller in rodent V1, suggesting that the modulatory function is well-conserved among varying mammalian species.

\section{Results}

Effects of ACh on visual responses and the laminar distribution. To understand how ACh modulates visual responses in V1 of anesthetized rats, we performed extracellular single-unit recordings of neuronal activity before, during, and after the administration of ACh. ACh was seen to cause either facilitatory or suppressive effects in V1 cells. Figure 1 shows the peri-stimulus time histograms (PSTHs) of visual responses recorded from two simple cells. Figure 1a shows an example of response facilitation by ACh. Assuming 100\% as the control response (top row), the response increased to $202 \%$ with ACh administration (middle row) and recovered to its preadministration level after the cessation of ACh administration (121\% of the control response; bottom row). In 
a
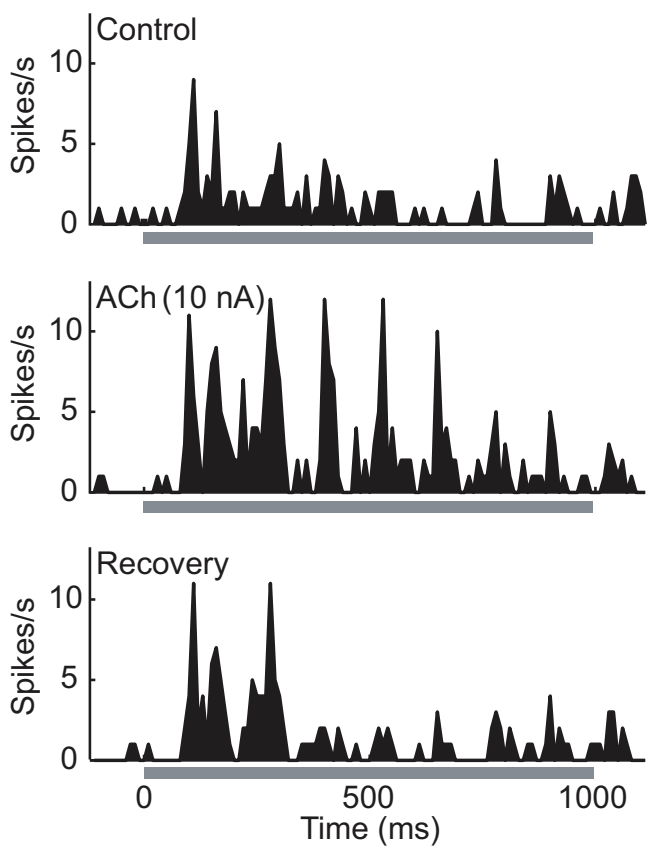

b
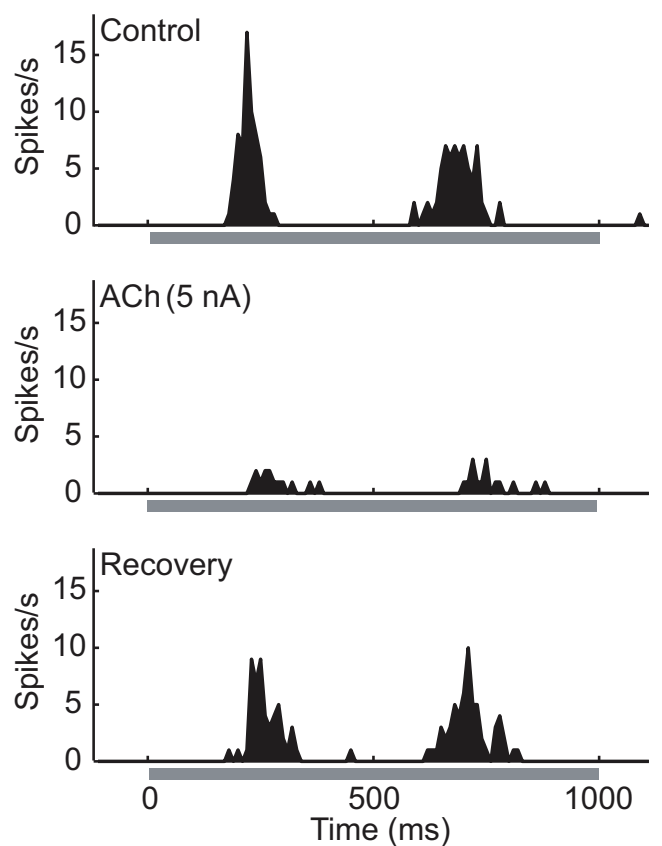

Figure 1 Facilitatory and suppressive effects of ACh on the visual responses of primary visual cortex (V1) neurons. Each histogram shows a peri-stimulus time histogram (PSTH) of visual responses to a drifting sinusoidal grating stimulus with optimal parameters ((a), spatial frequency: 0.02 cycles/degree, temporal frequency: $8 \mathrm{~Hz}$; (b), spatial frequency: 0.1 cycles/degree, temporal frequency: $2 \mathrm{~Hz}$ ) presented for $1 \mathrm{~s}$ (gray underline). Examples of neurons facilitated (a) and suppressed (b) by ACh. Top, middle, and bottom: PSTHs of visual responses obtained before (Control), during $(\mathrm{ACh})$, and after (Recovery) ACh administration ((a), $10 \mathrm{nA}$; (b), $5 \mathrm{nA})$, respectively. Number of trials: 10, bin width: $10 \mathrm{~ms}$.

the other cell (Fig. 1b), ACh administration had a suppressive effect, reducing the response magnitude to $23 \%$ of the control response, indicating that the modulatory effects of $\mathrm{ACh}$ on firing rate vary from cell to cell.

We then quantitatively and statistically classified these ACh effects by comparing the visual responses between Control and ACh conditions (see Methods). Among the 99 recorded cells, 39 (40\%), 28 $(28 \%)$, and $32(32 \%)$ were categorized as facilitated, suppressed, and no-effect cells, respectively (Fig. 2a). Next, we examined the relationship between ACh effects and cell types, where regular-spiking (RS, $n$ $=89$ ) and fast-spiking (FS, $n=10$ ) cells were classified electrophysiologically based on their spike waveforms (see Methods) ${ }^{32}$. The RS cells were categorized into 34 (38\%) facilitated, 24 (27\%) suppressed, and 31 (35\%) no-effect cells, while the FS cells were $5(50 \%), 4(40 \%)$, and $1(10 \%)$, respectively. There was no statistical difference in the occurrence rate of ACh effects between the two cell types $(P=0.276$, $\chi^{2}$ test). Moreover, no significant difference was observed between simple $(n=18)$ and complex $(n=81)$ cells, where facilitated, suppressed, and no-effect were $28 \%, 33 \%$, and $39 \%$, respectively, for simple cells and $42 \%, 27 \%$, and $31 \%$ for complex cells $(P=0.537$, $\chi^{2}$ test). We therefore pooled the RS and FS cells, and the simple and complex cells for the following analyses.

We also histologically reconstructed the laminar positions of the recording sites for all recorded cells $(n=99$; Fig. 2 b), finding that facilitated, suppressed, and no-effect cells were observed across all cortical layers and showed no significant laminar bias $(P=0.894$, $\chi^{2}$ test).

Cholinergic gain control in rat V1. To examine the effects of ACh on the relationship between the stimulus contrast (input) and response magnitude (output) of a single cell, we tested nine stimulus contrasts of grating stimuli in the presence or absence of $\mathrm{ACh}$ and constructed the corresponding contrast-response functions of the visual responses. Figure $3 \mathbf{a}$ is an explanatory schema of a contrast-response curve represented as a Naka-Rushton function.
The parameters of the function are useful for quantitatively assessing the shape of the contrast-response curve. $\mathrm{R}_{\max }$ is the maximal response, $\mathrm{C}_{50}$ the contrast that elicits half-maximal response, and $\mathrm{b}$ the background discharge measured during the presentation of a blank stimulus with $0 \%$ contrast. There are at least three possible types of gain control in the contrast response function: baseline control (Fig. 3b), contrast gain control (Fig. 3c), and response gain control (Fig. 3d) ${ }^{33,34}$. They are discriminable by changes in the parameters of the Naka-Rushton function. Baseline control is a contrast-independent modulation characterized by a change in $b$. On the other hand, both contrast gain control and response gain control are contrast-dependent modulations marked by changes in $\mathrm{C}_{50}$ and $\mathrm{R}_{\max }$, respectively. To examine which type of gain control occurred in the modulated cells, we compared the parameters of fits of data obtained from Control and ACh conditions.

Figure 4 shows typical examples of ACh effects on the contrastresponse function. ACh differentially modulated the shapes of the function for individual cells. Figure $4 a$ and $c$ show response gain control induced by $\mathrm{ACh}$, where the visual responses were enhanced (Fig. 4a) or suppressed (Fig. 4c) in proportion to the magnitude of the control response. On the other hand, in the two cells shown in Fig. $4 \mathrm{~b}$ and $\mathrm{d}, \mathrm{ACh}$ shifted the contrast-response curve upward (Fig. 4b) or downward (Fig. 4d) over the whole range of the stimulus contrasts, i.e. baseline control. Thus, ACh caused both response facilitation and suppression in a contrast-dependent and -independent manner.

To determine what percentage of modulated cells $(n=67)$ showed baseline control, we examined ACh effects on background discharge. A significant increase and decrease of background discharge by ACh was observed in 23 of the 39 facilitated cells and 6 of the 28 suppressed cells, respectively ( $P<0.05$, Mann-Whitney U-test). Thus, baseline control was shown in $29(=23+6)$ modulated cells, while the remaining 38 cells showed contrast-dependent gain control only. The 29 cells showing baseline control may also have contrastdependent gain control. To investigate whether those cells are 
a

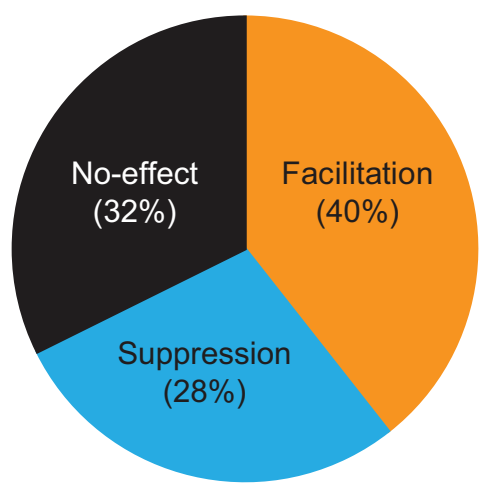

b

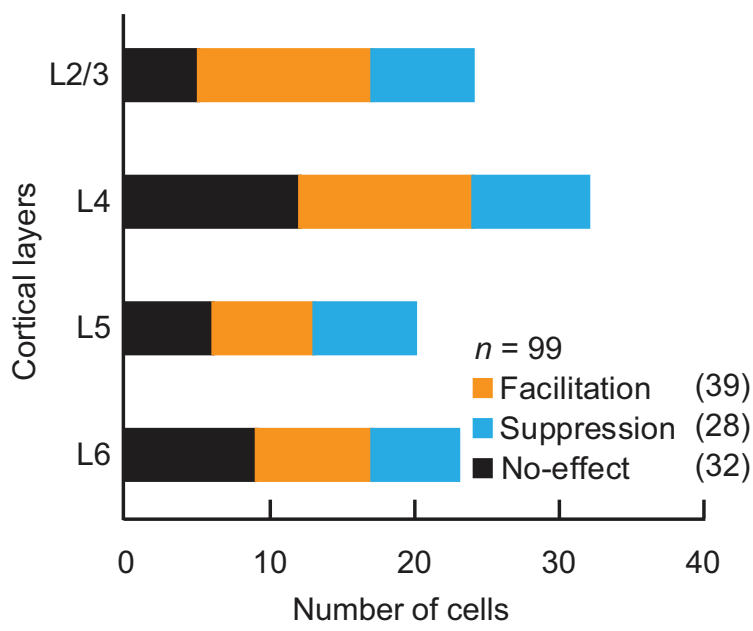

Figure $2 \mid$ Effects of ACh on layer (L) distribution in V1. (a): Pie chart illustrating the proportion of three ACh modulatory effects on neuronal responses in V1. Cells were categorized as facilitated (39 cells), suppressed (28 cells), or no-effect (32 cells). (b): V1 neurons $(n=99)$ were reconstructed from the laminar positions of the recording sites on the basis of histological observations. Each column shows the number of cells facilitated (orange columns), suppressed (blue columns), and unaffected (black columns) by microiontophoretically administered ACh. ACh effects were observed across all cortical layers without significant laminar bias $\left(P=0.894, \chi^{2}\right.$ test $)$.

attributable to baseline control only, we subtracted the background discharge from the visual response and compared the result between Control and ACh conditions. If ACh caused baseline control only, its facilitatory/suppressive effects should disappear after the subtraction. This indeed occurred in 10 of the 23 facilitated and 2 of the 6 suppressed cells, indicating that the remaining 17 modulated cells (facilitated cells, $n=13$; suppressed cells, $n=4$ ) had contrastdependent gain control under the ACh condition. Therefore, in total,
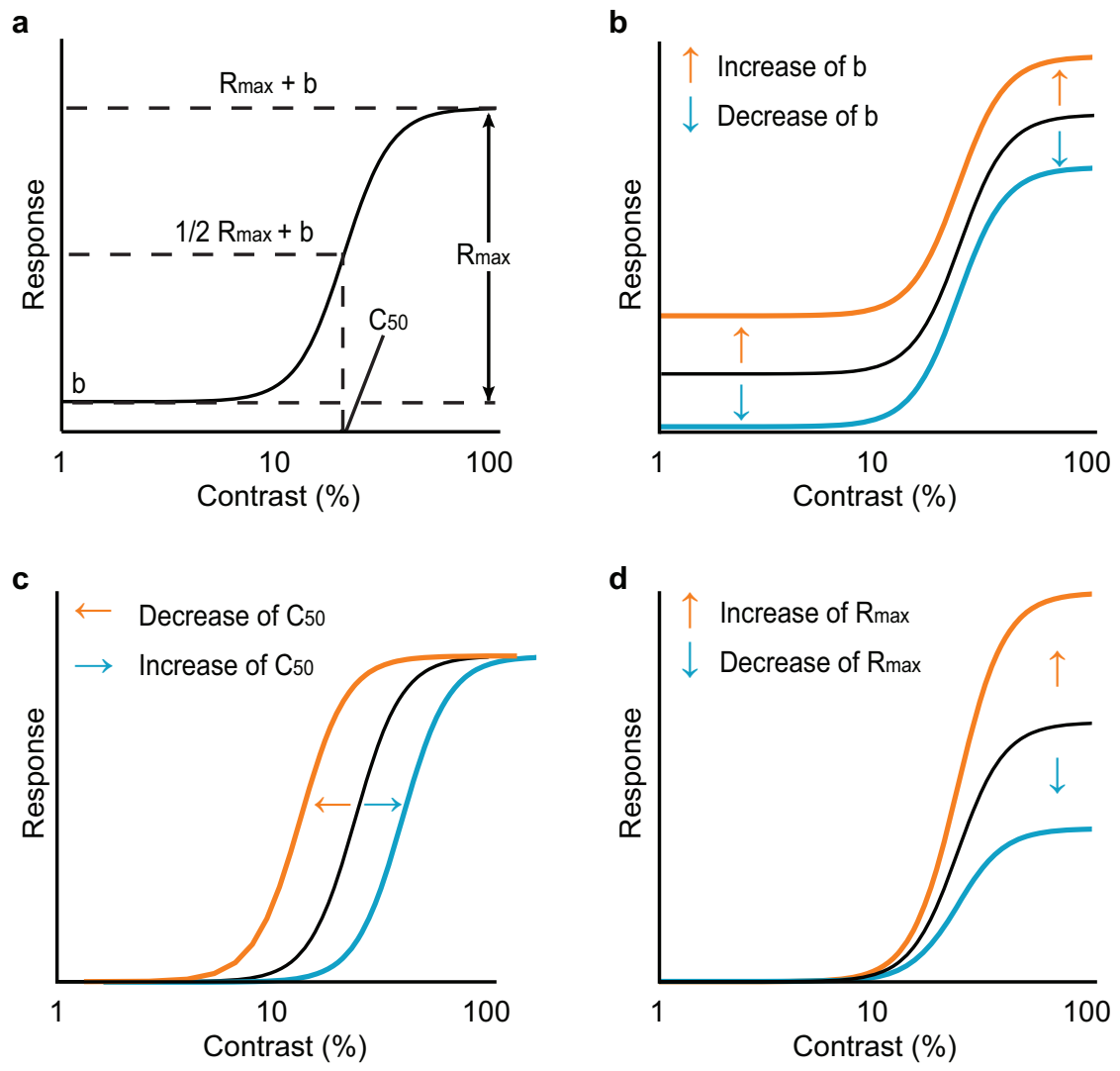

Figure 3 Naka-Rushton function and three possible types of gain control in the contrast-response function. (a): The contrast-response tuning curve was fitted using the Naka-Rushton function, where $\mathrm{R}_{\max }$ is the peak (maximal) response, $\mathrm{b}$ the background discharge, and $\mathrm{C}_{50}$ the contrast value at $1 / 2 \mathrm{R}_{\max }$ (contrast sensitivity). (b-d): Three kinds of gain control are considered: baseline control (b), contrast gain control (c), and response gain control (d), which are characterized by changes in $b, C_{50}$, and $\mathrm{R}_{\max }$, respectively. For example, response facilitation (orange) and suppression (blue) modulates the contrast-response function differently according to the type of gain control (see arrows). 
a

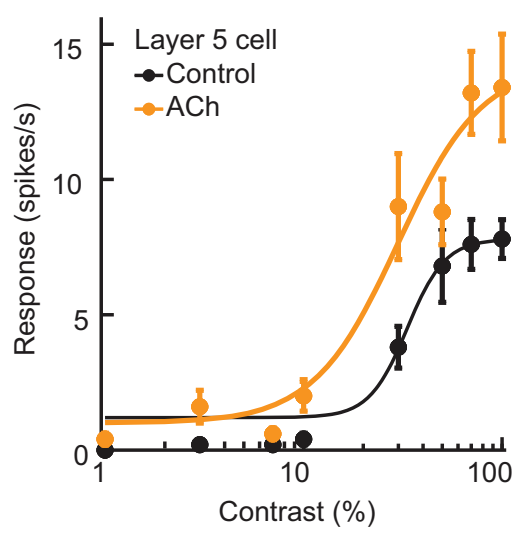

c

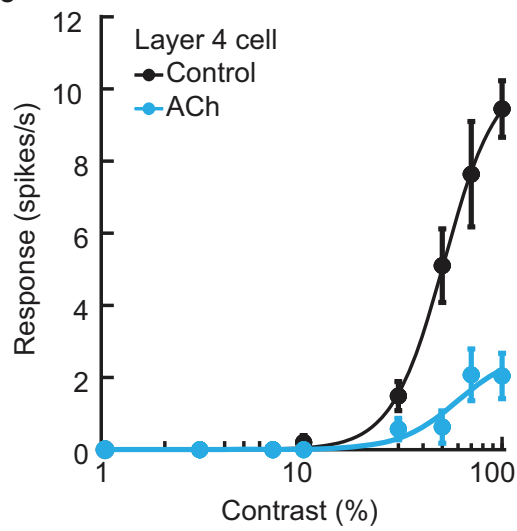

b

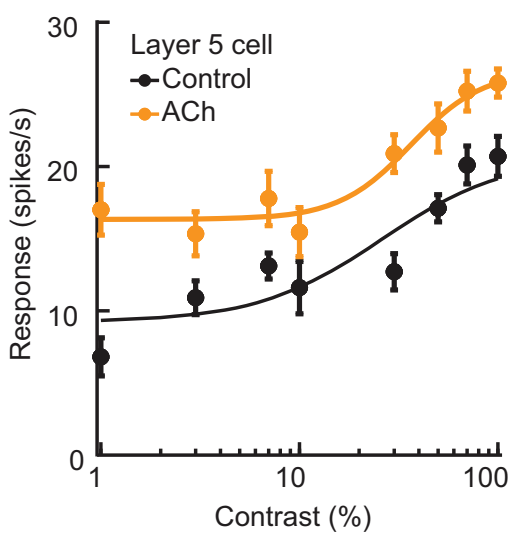

d

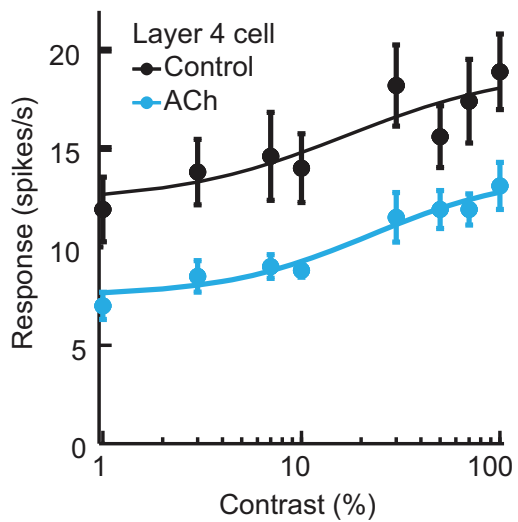

Figure 4 Typical effects of ACh on the contrast-response function of single V1 cells. Fits were obtained for contrast-response functions under no drug condition (Control: black dots and line) and ACh administration (ACh: colored dots and line). Visual responses were facilitated (a) and suppressed (c) in proportion to a stimulus contrast showing response gain control. On the other hand, ACh was found to increase (b) or decrease (d) the background discharge, shifting the contrast-response functions upward (b) or downward (d), i.e. baseline control. Thus, at least 4 types of ACh effects were observed: contrast-dependent and -independent facilitation and suppression. Error bars $=$ SEM.

the contrast-dependent gain control was observed in $82 \%(55 / 67)$ of modulated cells, while the remaining 18\% (12/67) were baseline control only.

The observed contrast-dependent gain control can attribute to: 1) contrast gain control; 2) response gain control; or 3) both. For example, a decrease in $\mathrm{C}_{50}$ (orange line; Fig. $3 \mathrm{c}$ ) or increase in $\mathrm{R}_{\max }$ (orange line; Fig. 3d) causes the response area of the contrast-response function to increase, i.e. response facilitation. To examine which gain control contributes more dominantly to response facilitation and suppression in our samples $(n=55)$, we compared the changes in $\mathrm{R}_{\max }$ and $\mathrm{C}_{50}$ between Control and ACh conditions (Fig. 5). Figure 5a shows ACh-induced changes in $\mathrm{R}_{\max }$ and $\mathrm{C}_{50}$ of facilitated (orange circles, $n=29$ ) and suppressed (blue circles, $n=$ $26)$ cells. ACh significantly increased and decreased $\mathrm{R}_{\max }(P<0.001$, Wilcoxon signed-rank test) by a factor of 2.4 and 0.4 in facilitated and suppressed cells, respectively (mean \pm SEM; change rate, facilitated cells: $2.4 \pm 0.3$, suppressed cells: $0.4 \pm 0.1$ ). $\mathrm{C}_{50}$ was also modulated by ACh. It was increased or decreased in both facilitated and suppressed cells (mean \pm SEM; change rate, facilitated cells: $1.2 \pm 0.2$, suppressed cells: $1.3 \pm 0.2$ ), and neither the facilitatory nor suppressive effects on $\mathrm{C}_{50}$ were statistically significant (facilitated cells: $P=$ 0.315 , suppressed cells: $P=0.970$, Wilcoxon signed-rank test). Thus, contrast-dependent response facilitation and suppression clearly corresponded to changes in $\mathrm{R}_{\max }$, but not to changes in $\mathrm{C}_{50}$. However, in a certain population of cells, ACh-induced changes in $\mathrm{C}_{50}$ did seem to contribute to the contrast-dependent facilitation and suppression, as $\mathrm{C}_{50}$ decreased (pale orange circles, $n=6$ ) or increased (pale blue circles, $n=4$ ) by a value larger than 1 SD from the population average, respectively. These cells were of various cell types (RS: $n=8$, FS: $n=2$; simple: $n=1$, complex: $n=9$ ) and were distributed across all cortical layers (layers 2/3: $n=4$, layer 4: $n=2$, layer $5: n=2$, layer $6: n=2$ ).

We finally constructed the contrast-response curves of the population responses for the 55 cells with contrast-dependent gain control (Fig. 5b and c). We first subtracted background discharges from the visual responses of modulated cells to remove any contrast-independent modulatory effects, and then normalized and averaged the subtracted responses. The population data for both the facilitated (Fig. 5b) and suppressed (Fig. 5c) cells clearly demonstrated that ACh modulated the response gain, but not the contrast gain in rodent $\mathrm{V} 1$ in accordance with previous studies on primates ${ }^{11,12,15}$ and tree shrews $^{17}$

\section{Discussion}

In this study, we investigated cholinergic effects on gain control in rat V1 by combining extracellular single-unit recordings and local microiontophoretic administration of ACh, finding that ACh caused an increase or decrease in the response gain of individual cells, resulting in response facilitation or suppression, respectively.

The effects of ACh in V1 have been examined in other species including macaque monkeys $\mathrm{s}^{11-13,15}$, marmosets ${ }^{14,16}$, tree shrews ${ }^{17}$, and cats $^{18-22}$. Those studies all found that ACh causes facilitatory or suppressive effects on individual cells. However, relatively fewer studies focused on the cholinergic modulation in the rodent visual cortex $^{24}$. Thus, it remains unknown how ACh modulates the contrast-response relationship in rodents. Here we found that ACh 
a

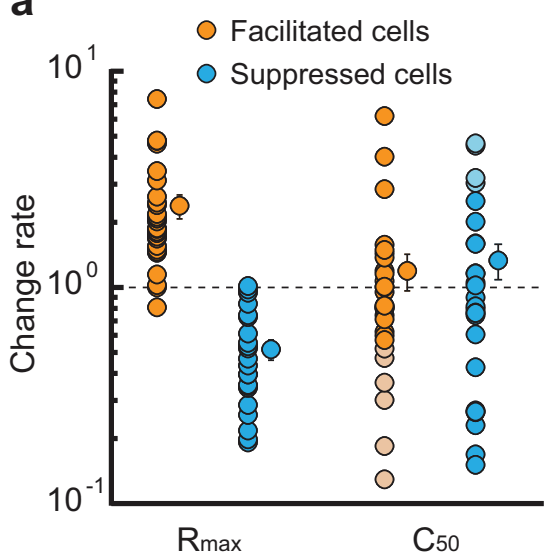

b

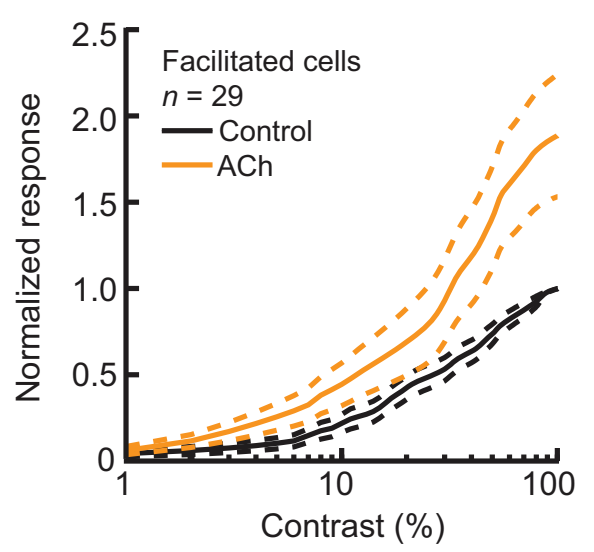

C

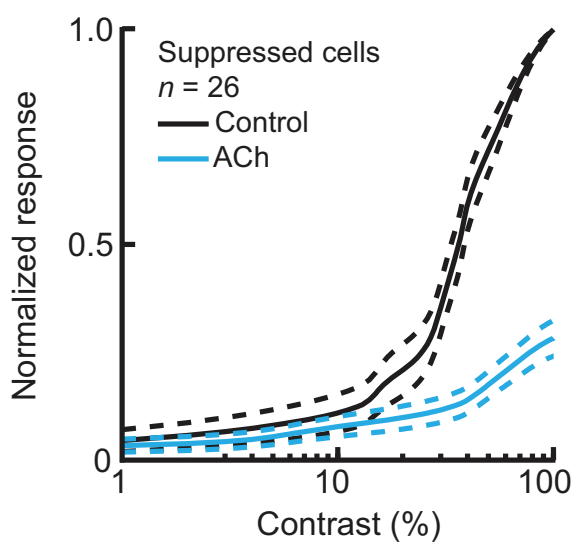

Figure 5 Response gain control by ACh. Population data of the contrast-response functions and parameters obtained from cells showing response modulations in visual responses by ACh except for those cells showing baseline control only (facilitated cells: orange, $n=29$; suppressed cells: blue, $n=26$ ). (a): ACh-induced changes in $\mathrm{R}_{\max }$ (left) and $\mathrm{C}_{50}$ (right). Raw data points were plotted with their average values (mean \pm SEM). Following ACh administration, $\mathrm{R}_{\max }$ values increased and decreased by an average factor of 2.4 or 0.4 for facilitated and suppressed cells, respectively. Both the facilitatory and suppressive effects on $\mathrm{R}_{\max }$ were statistically significant $\left(P<0.001\right.$, Wilcoxon signed-rank test). ACh changed $\mathrm{C}_{50}$ bi-directionally in both modulated cells (mean \pm SEM; change rate, facilitated cells: $1.2 \pm 0.2$, suppressed cells: $1.3 \pm 0.2$ ) and neither facilitatory nor suppressive effects were statistically significant (facilitated cells: $P=0.315$, suppressed cells: $P=0.970$, Wilcoxon signed-rank test). Circles with pale color indicate facilitated and suppressed cells whose $\mathrm{C}_{50}$ were decreased (pale orange circles, $n=6$ ) or increased (pale blue circles, $n=4$ ) by more than 1 SD from the population average, respectively. (b-c): After subtracting the background discharge from the responses of the facilitated (b) and suppressed (c) cells, we normalized and averaged the responses to show contrast-response curves of the population responses. Control and ACh data are shown by the black and color lines, respectively. Dashed lines show SEM.

predominantly controls response gain in rodent $\mathrm{V} 1$, a result consistent with those seen in primate ${ }^{11,12,15}$ and tree shrew ${ }^{17}$, suggesting that ACh works as a gain controller in the visual cortex of diverse mammalian species.

Yet it has been reported in primate V1 that ACh does not change $\mathrm{C}_{50}{ }^{11,12,15}$. In this study, $\mathrm{ACh}$-induced changes in $\mathrm{C}_{50}$ seem to contribute to the contrast-dependent facilitation and suppression in a small population of cells ( $18 \%$ of contrast-dependently modulated cells), but the majority of cells showed no significant change in $\mathrm{C}_{50}$. These results suggest that the effects of $\mathrm{ACh}$ on not only response gain, but also contrast sensitivity are similar between primate and rodent $\mathrm{V} 1$.

ACh has been known to exert its modulatory actions via two distinct AChR subclasses, nicotinic ACh receptors (nAChRs) and muscarinic ACh receptors (mAChRs) ${ }^{28}$. Recent neuropharmacological studies using primates have directly shown that both AChRs are responsible for response gain control ${ }^{11,12,15}$. In primate $\mathrm{V} 1$, microiontophoretic administration of ACh caused response gain control of visual responses, with modulatory effects that were completely or partially blocked by administration of antagonists specific for nAChRs or mAChRs ${ }^{15}$. To date, no equivalent studies have been done on rodent, however.

Interestingly, primates showed a laminar bias for the contribution of the receptor subclasses, as nAChRs mainly operated in the thalamocortical layer and mAChRs operated across all cortical layers ${ }^{11,12,15}$. These physiological observations are in accordance with the laminar distribution of corresponding receptor subclass proteins in primate $\mathrm{V} 1$, where $\mathrm{nAChRs}$ are predominately expressed in layer 4 and $\mathrm{mAChRs}$ are observed without laminar bias ${ }^{11,35-38}$. The same laminar bias of receptor subclass proteins has been also reported in rodent $\mathrm{V}^{39-42}$, suggesting that not only is the functional role of $\mathrm{ACh}$ as a gain controller for the contrast-response relationship conserved among species, so too is the involved AChR subclasses.

What is the functional role of the response gain control by ACh? First, ACh maintains the response gain at a certain level for normal visual function by being constitutively released to the visual cortex ${ }^{43}$.
This observation is supported by a previous study in which the depletion of ACh by lesioning the basal forebrain severely reduces the response magnitude of many V1 neurons in $\mathrm{cat}^{20}$. Thus, a basal level of ACh seems to play an important role in normal visual information processing.

ACh has also been proposed to improve an animal's visual performance including properties like the detectability and discriminability of visual stimuli during the attentional state by changing the response gain. Dan and her colleagues have shown that optical stimulation of the cholinergic neurons of the basal forebrain in transgenic rat expressing the light-gated cation channel, Channelrhodopsin-2, improves performance in stimulus-contrast detection tasks (personal communication with Dr. Yang Dan). Since optical stimulation of these neurons influences various cortical areas, it is unclear which areas and which neuronal changes attributed to this result. Our current finding indicates the possibility that ACh-induced gain-changes in V1 mediate the effect. Moreover, Parikh and his colleagues measured intrinsic ACh concentration in the rat prefrontal cortex, finding that the detectability of a visual cue is positively and strongly correlated with the ACh level, and that success or failure in a cue detection task is predictable from the ACh level in the pre-cue period ${ }^{6}$. Although they did not measure ACh concentration in V1, it is expected that ACh released there also contributes to improved stimulus detectability by changing the response gain of the visual response. Further study is needed to clarify this point.

\section{Methods}

All experimental protocols were approved by the Research Ethics Committee of Osaka University. All procedures were carried out in accordance with the regulations of the Animal Care Committee of the Osaka University Medical School and National Institutes of Health guidelines for the care of experimental animals. All efforts were made to reduce the number of animals used.

Preparation. Twelve anesthetized male Long-Evans rats weighing 250-400 g were used to record visual responses in V1. Animal preparation procedures are described in detail elsewhere ${ }^{44,45}$. Each animal was anesthetized by intraperitoneal injection of urethane (Kishida Chemical, Osaka, Japan; $1.5 \mathrm{~g} \cdot \mathrm{kg}^{-1}$ ) and supplemented as 
necessary. The animals were then placed in a stereotaxic apparatus and their body temperature was maintained at about $37^{\circ} \mathrm{C}$ by a heating pad. A local anesthetic, lidocaine, was administered at pressure points and around surgical incisions. The electrocardiogram, electroencephalogram, and heart rate were continuously monitored throughout the experiment.

\section{Physiological recordings and microiontophoretic administration of ACh. We} performed extracellular single-unit recordings with microiontophoretic administration of ACh. The skull was exposed and a small hole (less than $2 \mathrm{~mm}$ in diameter) was made above the monocular region of left $\mathrm{V} 1$ (coordinates: $1 \mathrm{~mm}$ anterior from the lambda and $3.5 \mathrm{~mm}$ lateral from the midline). A glass microelectrode was attached to a two-barreled drug pipette in which the barrels were filled with ACh (Nacalai Tesque, Kyoto, Japan; 500 mM, pH 4.5) and Ringer's solution ( $\mathrm{pH} 7.0)^{15,46}$. The tip of the recording electrode protruded 10-30 $\mu \mathrm{m}$ from the tip of the drug barrels. ACh was dissolved in distilled water, and then the $\mathrm{pH}$ of the solution was adjusted to 4.5 , as the value was used frequently in previous studies ${ }^{11-16,19-21}$ and the microiontophoresis of acidic solution with $\mathrm{pH}$ values higher than 3.0 have been confirmed to no affect visual responses ${ }^{11}$. The ejecting current was generally between +1 and $+100 \mathrm{nA}$; the retaining current was between -5 and $-15 \mathrm{nA}$. In every cell tested, the ejecting current was chosen as the current at which modulatory effects were not markedly changed beyond this value (median:

$+33.5 \mathrm{nA}$ ). When a cell showed no modulatory effect by ACh administration, the current was increased maximally to $+100 \mathrm{nA}$. To confirm that the modulatory effects were not due to a current effect, we checked the effects of the microiontophoretic administration of Ringer's solution using the same range of ejecting currents. No cell showed any change in amplitude of the spike waveform or firing rate during the microiontophoresis. The recording pipette was filled with $0.5 \mathrm{M}$ sodium acetate containing 4\% Pontamine sky blue (Direct Blue 1, Tokyo Kasei, Tokyo, Japan). Two or three dye marks were produced by passing tip-negative direct current at the end of each penetration $(100-200$ pulses of $8-10 \mu \mathrm{A}$ at $0.5 \mathrm{~Hz})$ for histological verification of the recording sites.

Visual stimulation. When single neuron activity was isolated, we manually assessed classical receptive field (CRF) properties, including optimal orientation, direction, spatial frequency (0.02-0.2 cycles/degree), and temporal frequency $(1-8 \mathrm{~Hz})$ of the stimulus using a hand-held projector. Subsequently, computer-generated visual stimuli were used to determine optimal parameters of the CRF quantitatively. A fullscreen stimulus of drifting sinusoidal grating was generated by custom-made MATLAB (The Mathworks, Natick, MA, USA) programs with Psychtoolbox ${ }^{47,48}$ and presented for $1 \mathrm{~s}$ monocularly on a CRT display monitor (CDM-F520, Sony, Tokyo, Japan; mean luminance: $30 \mathrm{~cd} / \mathrm{m}^{2}$; refresh rate: $100 \mathrm{~Hz}$; screen size: $40 \times 30 \mathrm{~cm}^{2}$ ) placed $24 \mathrm{~cm}$ in front of the right eye. The right eye was fixed with a metal ring to prevent eye movement and irrigated with sterile saline ${ }^{24,49}$.

We then presented a full-screen grating stimulus with optimal parameters at varying stimulus contrasts to obtain a contrast-response function. The neuronal response was measured while pseudorandomly changing the stimulus contrast, which included 9 contrast levels, $0 \%$ and eight logarithmic steps from 1-100\%. Background discharge was defined as the spike discharge during the presentation of a blank stimulus with $0 \%$ contrast. Each stimulus condition was pseudorandomly repeated ten times to construct a PSTH, and each stimulus presentation was interleaved with a blank screen with $0 \%$ contrast for $1 \mathrm{~s}$ to prevent any response adaptation. This method was supported by our preliminary experiments $(n=30)$, which showed no difference in contrast response functions between the first 3 and last 3 trials under the no drug condition. $\mathrm{R}_{\max }$ for the first 3 trials was $8.7 \pm 1.2$ spikes/s and last 3 trials was $7.9 \pm 1.0 \mathrm{spikes} / \mathrm{s}$ (mean $\pm \mathrm{SEM} ; r=0.862 ; P=0.164$, Wilcoxon signed-rank test), and $\mathrm{C}_{50}$ for the first 3 trials was $33.3 \pm 3.4 \%$ and last 3 trials was $34.4 \pm 3.4 \%$ (mean \pm SEM; $r=0.773 ; P=0.773$, Wilcoxon signed-rank test). Measurements were performed before, during, and after ACh administration, which we refer to as the Control, $\mathrm{ACh}$, and Recovery conditions, respectively.

Histology. After the recording experiments, animals were deeply anesthetized with sodium pentobarbital (Nembutal, Dainippon Sumitomo Pharma, Osaka, Japan; $200 \mathrm{mg} \cdot \mathrm{ml}^{-1} \mathrm{~kg}^{-1}$, i.p.) and perfused transcardially with $0.1 \mathrm{M}$ phosphate-buffered saline (PBS; $\mathrm{pH}$ 7.4) followed by 4\% paraformaldehyde in $0.1 \mathrm{M}$ PBS. Whole brains were obtained and immersed in 30\% sucrose in PBS for 36-48 h. Sixty-micrometerthick frozen parasagittal sections were sliced on a microtome and kept in PBS Sections were stained for cytochrome oxidase ${ }^{50}$. The laminar positions of the recording sites were then identified under a light microscope. Shrinking in the cortical tissues was corrected by taking the ratio of the measured dye mark distance and the distance calculated from the micrometer reading for single-unit recordings ${ }^{15,46}$.

Cell Classification. The fundamental (F0) and first harmonic (F1) components of averaged responses were computed from PSTHs that were compiled during each condition (Control, ACh, and Recovery). V1 neurons were classified as "simple" or "complex" based on the F1/F0 ratio (F1/F0 $\geq 1$ : simple cells; F1/F0 $<1$ : complex cells $)^{51}$. The F1 and the F0 components were used as the response magnitude for simple and complex cells, respectively.

Two types of cells, RS and FS, were classified on the basis of their spike waveforms: amplitude (the ratio of trough-to-peak amplitude), time-course of spikes (trough-topeak time), and end slope (slope at $0.25 \mathrm{~ms}$ after the trough of the waveform). The two populations could be clearly separated and classified as RS and FS cells, respectively. RS and FS cells showed significantly different values in amplitude (mean \pm SEM; RS
$0.51 \pm 0.02$, FS: $0.80 \pm 0.18 ; P<0.001$, unpaired $t$-test), time-course (mean \pm SEM; RS: $0.30 \pm 0.005 \mathrm{~ms}, \mathrm{FS}: 0.17 \pm 0.008 \mathrm{~ms} ; P<0.0001$, unpaired $t$-test), and end slope (mean \pm SEM; RS: $-0.05 \pm 0.007, \mathrm{FS}:-0.49 \pm 0.14 ; P<0.0001$, unpaired $t$-test).

Classification of ACh effects on contrast-response functions. The effects of ACh on the contrast-response curve were categorized according to a nonparametric analysis method described previously ${ }^{11,12,15}$, where the areas under the contrast-response curves (response area) were compared between Control and ACh conditions using the Mann-Whitney U-test $(\alpha=0.05)$. Statistically significant ACh-induced increases and decreases in the response area were classified as facilitation and suppression, respectively.

Fitting. To quantify the contrast sensitivity of the recorded neurons, we fitted the contrast-response relationship using the following equation (Naka-Rushton function $)^{52}$.

$$
\mathrm{R}=\mathrm{R}_{\max } \mathrm{C}^{\mathrm{n}} /\left(\mathrm{C}^{\mathrm{n}}+\mathrm{C}_{50}^{\mathrm{n}}\right)+\mathrm{b},
$$

where $\mathrm{R}$ is the neuronal response, $\mathrm{C}$ is the contrast of grating stimuli, and $\mathrm{b}$ is the background discharge. $\mathrm{R}_{\max }$ (maximal response), $\mathrm{n}$ (exponent of the power function, $>0$ ) and $\mathrm{C}_{50}$ (contrast for half of $\mathrm{R}_{\max }$ ) are free parameters.

1. Johnston, M. V., McKinney, M. \& Coyle, J. T. Neocortical cholinergic innervation: a description of extrinsic and intrinsic components in the rat. Exp. Brain Res. 43, 159-172 (1981)

2. Lehmann, J., Nagy, J. I., Atmadia, S. \& Fibiger, H. C. The nucleus basalis magnocellularis: the origin of a cholinergic projection to the neocortex of the rat. Neuroscience 5, 1161-1174 (1980).

3. Saper, C. B. Organization of cerebral cortical afferent systems in the rat. II. Magnocellular basal nucleus. J. Comp. Neurol. 222, 313-342 (1984).

4. Malcolm, J. L., Saraiva, P. \& Spear, P. J. Cholinergic and adrenergic inhibition in the rat cerebral cortex. Int. J. Neuropharmacol. 6, 509-527 (1967).

5. Stone, T. W. Cholinergic mechanisms in the rat somatosensory cerebral cortex. J. Physiol. 225, 485-499 (1972).

6. Parikh, V., Kozak, R., Martinez, V. \& Sarter, M. Prefrontal acetylcholine release controls cue detection on multiple timescales. Neuron 56, 141-154 (2007).

7. St Peters, M., Demeter, E., Lustig, C., Bruno, J. P. \& Sarter, M. Enhanced control of attention by stimulating mesolimbic-corticopetal cholinergic circuitry. J. Neurosci. 31, 9760-9771 (2011).

8. Sarter, M., Hasselmo, M. E., Bruno, J. P. \& Givens, B. Unraveling the attentional functions of cortical cholinergic inputs: interactions between signal-driven and cognitive modulation of signal detection. Brain Res. Rev. 48, 98-111 (2005).

9. Mayo, W. et al. Infusion of neurosteroids into the nucleus basalis magnocellularis affects cognitive processes in the rat. Brain Res. 607, 324-328 (1993).

10. Maskos, U. et al. Nicotine reinforcement and cognition restored by targeted expression of nicotinic receptors. Nature 436, 103-107 (2005).

11. Disney, A. A., Aoki, C. \& Hawken, M. J. Gain modulation by nicotine in macaque V1. Neuron 56, 701-713 (2007)

12. Disney, A. A., Aoki, C. \& Hawken, M. J. Cholinergic suppression of visual responses in primate V1 is mediated by GABAergic inhibition. J. Neurophysiol. 108, 1907-1923 (2012)

13. Herrero, J. L. et al. Acetylcholine contributes through muscarinic receptors to attentional modulation in V1. Nature 454, 1110-1114 (2008).

14. Roberts, M. J. et al. Acetylcholine dynamically controls spatial integration in marmoset primary visual cortex. J. Neurophysiol. 93, 2062-2072 (2005).

15. Soma, S., Shimegi, S., Osaki, H. \& Sato, H. Cholinergic modulation of response gain in the primary visual cortex of the macaque. J. Neurophysiol. 107, 283-291 (2012).

16. Zinke, W. et al. Cholinergic modulation of response properties and orientation tuning of neurons in primary visual cortex of anaesthetized Marmoset monkeys. Eur. J. Neurosci. 24, 314-328 (2006).

17. Bhattacharyya, A., Biessmann, F., Veit, J., Kretz, R. \& Rainer, G. Functional and laminar dissociations between muscarinic and nicotinic cholinergic neuromodulation in the tree shrew primary visual cortex. Eur. J. Neurosci. 35, 1270-1280 (2012).

18. Müller, C. M. \& Singer, W. Acetylcholine-induced inhibition in the cat visual cortex is mediated by a GABAergic mechanism. Brain Res. 487, 335-342 (1989).

19. Murphy, P. C. \& Sillito, A. M. Cholinergic enhancement of direction selectivity in the visual cortex of the cat. Neuroscience 40, 13-20 (1991)

20. Sato, H., Hata, Y., Hagihara, K. \& Tsumoto, T. Effects of cholinergic depletion on neuron activities in the cat visual cortex. J. Neurophysiol. 58, 781-794 (1987).

21. Sato, H., Hata, Y., Masui, H. \& Tsumoto, T. A functional role of cholinergic innervation to neurons in the cat visual cortex. J. Neurophysiol. 58, 765-780 (1987).

22. Sillito, A. M. \& Kemp, J. A. Cholinergic modulation of the functional organization of the cat visual cortex. Brain Res. 289, 143-155 (1983).

23. Origlia, N., Valenzano, D. R., Moretti, M., Gotti, C. \& Domenici, L. Visual acuity is reduced in alpha 7 nicotinic receptor knockout mice. Invest. Ophthalmol. Vis. Sci. 53, 1211-1218 (2012)

24. Goard, M. \& Dan, Y. Basal forebrain activation enhances cortical coding of natural scenes. Nat. Neurosci. 12, 1444-1449 (2009). 
25. Gil, Z., Connors, B. W. \& Amitai, Y. Differential regulation of neocortical synapses by neuromodulators and activity. Neuron 19, 679-686 (1997).

26. Gulledge, A. T., Park, S. B., Kawaguchi, Y. \& Stuart, G. J. Heterogeneity of phasic cholinergic signaling in neocortical neurons. J. Neurophysiol. 97, 2215-2229 (2007).

27. Kimura, F., Fukuda, M. \& Tsumoto, T. Acetylcholine suppresses the spread of excitation in the visual cortex revealed by optical recording: possible differential effect depending on the source of input. Eur. J. Neurosci. 11, 3597-3609 (1999).

28. Lucas-Meunier, E., Fossier, P., Baux, G. \& Amar, M. Cholinergic modulation of the cortical neuronal network. Pflugers. Arch. 446, 17-29 (2003).

29. Lucas-Meunier, E. et al. Involvement of nicotinic and muscarinic receptors in the endogenous cholinergic modulation of the balance between excitation and inhibition in the young rat visual cortex. Cereb. Cortex 19, 2411-2427 (2009).

30. McCormick, D. A. \& Prince, D. A. Two types of muscarinic response to acetylcholine in mammalian cortical neurons. Proc. Natl. Acad. Sci. U. S. A. 82, 6344-6348 (1985).

31. McCormick, D. A. \& Prince, D. A. Mechanisms of action of acetylcholine in the guinea-pig cerebral cortex in vitro. J. Physiol. 375, 169-194 (1986).

32. Niell, C. M. \& Stryker, M. P. Highly selective receptive fields in mouse visual cortex. J. Neurosci. 28, 7520-7536 (2008).

33. Sengpiel, F., Baddeley, R. J., Freeman, T. C., Harrad, R. \& Blakemore, C. Different mechanisms underlie three inhibitory phenomena in cat area 17. Vision Res. 38, 2067-2080 (1998)

34. Williford, T. \& Maunsell, J. H. Effects of spatial attention on contrast response functions in macaque area V4. J. Neurophysiol. 96, 40-54 (2006).

35. Disney, A. A. \& Aoki, C. Muscarinic acetylcholine receptors in macaque V1 are most frequently expressed by parvalbumin-immunoreactive neurons. J. Comp. Neurol. 507, 1748-1762 (2008).

36. Disney, A. A., Domakonda, K. V. \& Aoki, C. Differential expression of muscarinic acetylcholine receptors across excitatory and inhibitory cells in visual cortical areas V1 and V2 of the macaque monkey. J. Comp. Neurol. 499, 49-63 (2006).

37. Han, Z. Y. et al. Localization of $\left[{ }^{3} \mathrm{H}\right]$ nicotine, $\left[{ }^{3} \mathrm{H}\right]$ cytisine, $\left[{ }^{3} \mathrm{H}\right]$ epibatidine, and $\left[{ }^{125} \mathrm{I}\right]$ alpha-bungarotoxin binding sites in the brain of Macaca mulatta. J. Comp. Neurol. 461, 49-60 (2003).

38. Mrzljak, L., Levey, A. I. \& Goldman-Rakic, P. S. Association of $\mathrm{m} 1$ and $\mathrm{m} 2$ muscarinic receptor proteins with asymmetric synapses in the primate cerebral cortex: morphological evidence for cholinergic modulation of excitatory neurotransmission. Proc. Natl. Acad. Sci. U. S. A. 90, 5194-5198 (1993).

39. Clarke, P. B., Pert, C. B. \& Pert, A. Autoradiographic distribution of nicotine receptors in rat brain. Brain Res. 323, 390-395 (1984).

40. Levey, A. I., Kitt, C. A., Simonds, W. F., Price, D. L. \& Brann, M. R. Identification and localization of muscarinic acetylcholine receptor proteins in brain with subtype-specific antibodies. J. Neurosci. 11, 3218-3226 (1991).

41. Volpicelli, L. A. \& Levey, A. I. Muscarinic acetylcholine receptor subtypes in cerebral cortex and hippocampus. Prog. Brain Res. 145, 59-66 (2004).

42. Zilles, K. et al. Distribution of cholinergic receptors in the rat and human neocortex. Exs. 57, 212-228 (1989).

43. Jiménez-Capdeville, M. E. \& Dykes, R. W. Changes in cortical acetylcholine release in the rat during day and night: differences between motor and sensory areas. Neuroscience 71, 567-579 (1996)
44. Shimegi, S., Ichikawa, T., Akasaki, T. \& Sato, H. Temporal characteristics of response integration evoked by multiple whisker stimulations in the barrel cortex of rats. J. Neurosci. 19, 10164-10175 (1999).

45. Shimegi, S., Akasaki, T., Ichikawa, T. \& Sato, H. Physiological and anatomical organization of multiwhisker response interactions in the barrel cortex of rats. J. Neurosci. 20, 6241-6248 (2000)

46. Sato, H., Katsuyama, N., Tamura, H., Hata, Y. \& Tsumoto, T. Mechanisms underlying orientation selectivity of neurons in the primary visual cortex of the macaque. J. Physiol. 494, 757-771 (1996).

47. Brainard, D. H. The Psychophysics Toolbox. Spat. Vis. 10, 433-436 (1997)

48. Pelli, D. G. The VideoToolbox software for visual psychophysics: transforming numbers into movies. Spat. Vis. 10, 437-442 (1997).

49. Montero, V. M., Brugge, J. F. \& Beitel, R. E. Relation of the visual field to the lateral geniculate body of the albino rat. J. Neurophysiol. 31, 221-236 (1968).

50. Wong-Riley, M. Changes in the visual system of monocularly sutured or enucleated cats demonstrable with cytochrome oxidase histochemistry. Brain Res. 171, 11-28 (1979).

51. Skottun, B. C. et al. Classifying simple and complex cells on the basis of response modulation. Vision Res. 31, 1079-1086 (1991).

52. Naka, K. I. \& Rushton, W. A. S-potentials from luminosity units in the retina of fish (Cyprinidae). J. Physiol. 185, 587-599 (1966).

\section{Acknowledgements}

We thank Dr. Peter Karagiannis for improving the English of the manuscript. This work was supported by KAKENHI, 21500369 to H. Sato, and 22500573 to S. Shimegi. S. Soma was supported by the Japan Society for the Promotion of Science Research Fellowships.

\section{Author contributions}

S. Soma, S. Shimegi, and H.S. formed conception and design of research; S. Soma, and S. Shimegi performed experiments; S. Soma, S. Shimegi, and N.S. analyzed data; all authors interpreted results of experiments; S. Soma prepared figures; S. Soma and S. Shimegi drafted manuscript; all authors edited and revised the manuscript. All authors approved the final version of the manuscript.

\section{Additional information}

Competing financial interests: The authors declare no competing financial interests.

License: This work is licensed under a Creative Commons

Attribution-NonCommercial-NoDerivs 3.0 Unported License. To view a copy of this license, visit http://creativecommons.org/licenses/by-nc-nd/3.0/

How to cite this article: Soma, S., Shimegi, S., Suematsu, N. \& Sato, H. Cholinergic modulation of response gain in the rat primary visual cortex. Sci. Rep. 3, 1138; DOI:10.1038/ srep01138 (2013) 